\section{NATIONAL ACTION PLAN FOR CHILD INJURY PREVENTION-LAUNCHING A ROADMAP FOR AN INJURY-FREE CHILDHOOD}

doi:10.1136/injuryprev-2012-040580b.6

G Baldwin*, C Pogostin, D Sleet, M Ballesteros, A Salazar, J Gilchrist, L Dorigo, M Huitric, G Myers, K Seiber. CDC, National Center for Injury Prevention and Control, Atlanta, USA

Background In 2009, more than 9000 children and adolescents 0-19-years-old in the USA died from an unintentional injury-with the main causes including motor vehicle crashes, suffocations, drownings, poisonings, fires, and falls. The National Action Plan for Child Injury Prevention (NAP) was drafted to guide essential actions needed to reduce the burden of childhood injuries in America.

Aims/Objectives/Purpose Provide an overview of the development process for the NAP; describe the NAP launch (April 2012) and implementation plan; and highlight ways others can use the NAP and the process of its development to inform their child injury prevention efforts.

Methods As part of the US response to the WHO/UNICEF World Report on Child Injury Prevention, CDC worked closely with 60+ partner organisations to identify what we know, where we need to go, and how to get there in child injury prevention-codifying 22 goals and over 120 strategies.

Results/Outcome The NAP is a concrete roadmap to strengthen the collection and interpretation of data and surveillance, promote research, enhance communications, improve education and training, advance health systems, and inform policy in child injury prevention.

Significance/Contribution to the field The NAP provides a framework for guiding national, state and local efforts to reduce childhood injuries. It offers, for the first time, a specific set of goals and actions that can be used by federal and state agencies, advocates, NGOs and policy makers to reduce injuries. It may serve as an example for other countries. 